\title{
FAKTOR - FAKTOR YANG MEMPENGARUHI MINAT KONSUMEN DALAM MENGGUNAKAN JASA TRANSPORTASI KRL / COMMUTER LINE DENGAN METODE ANALISIS FAKTOR
}

\author{
Besse Arnawisuda Ningsi ${ }^{1)}$ dan Ani Putriyani ${ }^{2)}$ \\ ${ }^{1)}$ Dosen Program Studi Matematika, Universitas Pamulang \\ ${ }^{2)}$ Mahasiswa Program Studi Matematika, Universitas Pamulang
}

\begin{abstract}
ABSTRAK
Tujuan penelitian ini adalah untuk mengetahui berapa faktor yang terbentuk melalui proses reduksi, untuk menentukan faktor mana yang paling dominan mempengaruhi minat konsumen dalam menggunakan jasa transportasi KRL Commuter Line, untuk mengetahui seberapa besar pengaruh faktor yang paling dominan mempengaruhi minat konsumen dalam menggunakan jasa transportasi KRL Commuter Line. Dalam penelitian ini, digunakan metode Analisis Faktor dengan teknik - teknik principal component analysis dengan menggunakan software SPSS. Analisis Faktor 7 tahapan, yaitu : (1) merumuskan masalah, (2) Uji Interpedensi Variabel, (3) membentuk matriks korelasi, (4) menentukan metode analisis faktor, (5) mengekstraksi faktor, (6) melakukan rotasi faktor - faktor, dan (7) menginterpretasikan faktor. Berdasarkan hasil penelitian, banyaknya faktor yang terbentuk dari proses reduksi adalah 7 faktor. Terdiri dari faktor satu $\left(\mathrm{F}_{1}\right)$ dengan nilai korelasi 0,608 , faktor dua $\left(\mathrm{F}_{2}\right)$ dengan nilai korelasi $-0,277$, faktor tiga $\left(\mathrm{F}_{3}\right)$ dengan nilai korelasi $-0,246$, faktor empat $\left(\mathrm{F}_{4}\right)$ dengan nilai korelasi 0,419, faktor lima $\left(F_{5}\right)$ dengan nilai korelasi 0,716 , faktor enam $\left(F_{6}\right)$ dengan nilai korelasi $-0,392$, faktor tujuh $\left(\mathrm{F}_{7}\right)$ dengan nilai korelasi 0,570. Faktor yang paling dominan mempengaruhi minat konsumen dalam menggunakan jasa transportasi KRL Commuter Line adalah faktor lima $\left(\mathrm{F}_{5}\right)$ dengan nilai korelasi 0,716 atau $71.6 \%$.
\end{abstract}

Kata kunci : Analisis faktor, minat konsumen, Principal Component Analysis.

\begin{abstract}
The purpose of this study was to find out how many factors were formed through the reduction process, to determine which factors most dominantly influence consumer interest in using KRL Commuter Line transportation services, to find out how much influence the most dominant factors influence consumer interest in using KRL Commuter transportation services Line. In this study, the Factor Analysis method was used with principal component analysis techniques using SPSS software. 7 stages of factor analysis, namely: (1) formulating a problem, (2) Variable Interference Test, (3) forming a correlation matrix, (4) determining factor analysis methods, (5) extracting factors, (6) rotating factors, and (7) interpret factors. Based on the results of the study, the number of factors formed from the reduction process is 7 factors. Consisting of one factor (F1) with a correlation value of 0.608 , factor two (F2) with a correlation value of -0.277 , factor three $(\mathrm{F} 3)$ with a correlation value of -0.246 , factor four (F4) with a correlation value of 0.419 , factor five (F5) with the correlation value is 0.716 , factor six (F6) with a correlation value of -0.392 , factor seven (F7) with a correlation value of 0.570 . The most dominant factor affecting consumer interest in using KRL Commuter Line transportation services is factor five (F5) with a correlation value of 0.716 or $71.6 \%$.
\end{abstract}

Keywords: Factor analysis, consumer interest, Principal Component Analysis. 


\section{PENDAHULUAN}

Dalam era globalisasi, perkembangan dan peranan sektor jasa makin cepat terutama didorong oleh kemajuan pesat dalam teknologi telekomunikasi dan inormasi. Perusahaan jasa pun mengalami pertumbuhan yang sangat cepat dan berkembang menjadi sangat kompleks. Persaingan bisnis antar perusahaan jasa sangat ketat. Perusahaan harus memberikan konsumen suatu jasa yang bermutu lebih baik, penyerahan lebih cepat dan pelayanan lebih baik daripada pesaingnya.

Perkembangan jasa transportasi dewasa ini sangat pesat, berbagai macam bentuk dan jenis alat transportasi banyak diciptakan oleh manusia untuk memberikan fasilitas bagi kehidupan mereka. Sarana transportasi merupakan bagian penting bagi kehidupan masyarakat sehari-hari. Transportasi memiliki peranan penting dalam segala aspek kehidupan, yaitu baik dari aspek sosial, ekonomi, lingkungan, politik, pertahanan, dan keamanan. Transportasi merupakan sarana perkembangan yang penting dalam roda perekonomian.

Ditinjau dari kebutuhan masyarakat yang semakin meningkat akan jasa transportasi, berdampak pada peningkatan jumlah pertumbuhan perusahaan yang bergerak pada bidang transportasi yang berlomba untuk memenuhi kebutuhan masyarakat tersebut, hal ini menciptakan persaingan bisnis dibidang jasa transportasi dimana setiap penyedia jasa transportasi menawarkan berbagai keunggulan baik dari segi fasilitas, pelayanan dan harga, sehingga setiap perusahaan harus memiliki strategi yang tepat untuk tetap bertahan, berkembang, dan memenangkan persaingan.

Berdasarkan pada uraian latar belakang diatas, maka peneliti akan mengadakan penelitian dengan judul "Faktor - Faktor yang Mempengaruhi Minat Konsumen dalam Menggunakan Jasa Transportasi KRL Commuter Line Dengan Metode Analisis Faktor".

Rumusan masalah dalam penelitian ini adalah sebagai berikut :

1) Berapa faktor yang terbentuk dari proses reduksi?

2) Faktor mana yang paling dominan mempengaruhi minat konsumen dalam menggunakan jasa transportasi KRL Commuter Line?

3) Seberapa besar pengaruh faktor yang paling dominan mempengaruhi minat konsumen dalam menggunakan jasa transportasi KRL Commuter Line? 
Batasan masalah diperlukan agar penelitian lebih optimal, adapun batasan masalah pada penelitian ini adalah sebagai berikut :

1) Penulis hanya mengambil sampel dari konsumen di Stasiun Tenjo.

2) Masalah yang diteliti adalah minat konsumen dalam menggunakan jasa transportasi KRL Commuter Line.

3) Faktor - faktor yang dianalisis adalah: pengaruh pelayanan, fasilitas, keamanan, kenyamanan, jarak tempuh, waktu tempuh, harga, lokasi terhadap minat konsumen dalam menggunakan jasa transportasi KRL Commuter Line.

\section{TINJAUAN PUSTAKA}

Secara matematis, analisis faktor agak mirip dengan regresi linear berganda, yaitu bahwa setiap variabel dinyatakan sebagai suatu kombinasi linear dari faktor yang mendasari (underying factors). Jumlah (amount) varian yang disumbangkan oleh suatu variabel dengan variabel lainya yang tercakup dlam analisis disebut communality. Kovariansi antara variabel yang diuraikan, dinyatakan dalam suatu common factor yang sedikit jumlahnya ditambah dengan faktor yang unik untuk seiap variabel. Faktor faktor ini tidak secara jelas terlihat. Kalau variabel - variabel dibakukan (distandardized). Maka faktor bisa ditulis sebagai berikut :

$X_{i}=\beta_{i 1} F_{1}+\beta_{i 2} F_{2}+\cdots+\beta_{i j} F_{j}+\cdots+\beta_{i m} F_{m}+\mu_{i}$

Keterangan :

$X_{i}=$ Variabel ke $-\mathrm{i}$ yang dibakukan (rata - rata nol, standar deviasinya satu)

$\beta_{i j} \quad=$ koefisien regresi parsial yang dibakukan untuk variabel I pada common factor ke $-\mathrm{j}$

$F_{j} \quad=$ Common factor $\mathrm{ke}-\mathrm{j}$

$\mu_{i} \quad=$ Faktor unik variabel ke $-\mathrm{i}$

M = Banyaknya common factor

Faktor unik tidak berkorelasi dengan semua faktor unik dan juga tidak berkolerasi dengan common factor, Common factor sendiri bisa dinyatakan sebagai kombinasi linear dari variabel - variabel yang terlihat atau terobservasi (the observed variable) hasil penelitian lapangan.

$F_{i}=W_{i 1} X_{1}+W_{i 2} X_{2}+\cdots+W_{i m} X_{m}$

Keterangan : 


$$
\begin{aligned}
& F_{i}=\text { Perkiraan faktor } \mathrm{ke}-\mathrm{i} \\
& W_{i}=\text { Timbangan atau koefisien nilai faktor } \mathrm{ke}-\mathrm{i} \\
& M=\text { Banyaknya variabel }
\end{aligned}
$$

Dimungkinkan untuk memilih timbangan (weight) atau koefisien nilai factor (factor score coefficient) sehingga faktor yang pertama menjelaskan sebagian besar varian seluruh variabel. Kemudian set timbangan yang kedua dapat dipilih, sehingga faktor yang kedua menyerap sebagian besar sisa varian, setelah diambil faktor yang pertama, dengan syarat bahwa faktor yang kedua tidak berkorelasi (orthogonal) dengan faktor pertama.

Prinsip yang sama dapat dipergunakan untuk memilih faktor selanjutnya, sebagai faktor tambahan, yaitu faktor ketiga. Jadi, faktor bisa diperkirakan atau diestimasi sehingga nilai faktor yang satu tidak berkorelasi dengan nilai faktor lainya.

Minat adalah kecendrungan dalam diri individu untuk tertarik pada sesuatu objek atau menyenangi sesuatu objek (Sumadi Suryabrata, 1988:109). Menurut Crow and Crow minat adalah pendorong yang menyebabkan seseorang memberi perhatian terhadap orang, sesuatu, aktivitas - aktivitas. Misalkan individu yang mempunyai minat terhadap belajar, maka akan terdorong untuk memberikan perhatian terhadap belajar tersebut.

Karakteristik minat :

1. Menimbulkan sikap positif terhadap sesuatu objek.

2. Adanya sesuatu yang menyenangkan yang timbul dari sesuatu objek itu.

3. Mengandung suatu pengharapan yang menimbulkan keinginan atau gairah untuk mendapatkan sesuatu yang menjadi minatnya.

Konsumen adalah setiap orang pemakai barang dan jasa yang tersedia dalam masyarakat, baik bagi kepentingan diri sendiri, keluarga, orang lain dan tidak untuk diperdagangkan.

Banyak para ahli yang mencoba mendefinisikan pengertian dari konsumen. Menurut para ahli hukum, konsumen adalah sebagai pemakai terakhir dari benda dan jasa yang diserahkan kepada mereka oleh penguasa. Menurut Philip Kotler, pengertian konsumen adalah semua individu dan rumah tangga yang membeli atau memperoleh barang atau jasa untuk di konsumsi pribadi. 
Minat konsumen merupakan perilaku konsumen yang menunjukan sejauh mana komitmennya untuk melakukan tindakan pembelian atau kegiatan penggunaan suatu jasa. Kebutuhan dan keinginan konsumen akan barang dan jasa berkembang dari masa ke masa dan mempengaruhi perilaku mereka. Minat konsumen tumbuh karena suatu motif berdasarkan atribut - atribut sesuai dengan keinginan dan kebutuhannya dalam menggunakan suatu pelayanan jasa. Minat konsumen adalah hasil dari evaluasi terhadap merek atau jasa.

Kecendrungan seorang konsumen menunjukan minat terhadap suatu produk atau jasa dapat dilihat berdasarkan ciri - ciri :

1) Kemauan untuk mencari informasi terhadap suatu produk atau jasa.

2) Kesediaan untuk membayar barang atau jasa.

3) Menceritakan hal yang positif.

4) Kecendrungan untuk merekomendasikan.

\section{METODOLOGI PENELITIAN}

Waktu penelitian ini berlangsung di bulan April - Mei 2018. Tempat penelitian ini dilaksanakan di Stasiun Tenjo. Agar penelitian ini sesuai dengan apa yang diharapkan maka penulis membatasi ruang lingkup penelitian, yaitu konsumen yang memilih jasa transportasi KRL Commuter Line.

Dalam penelitian ini, populasi penelitian mengacu pada konsumen di Stasiun Tenjo yang memilih jasa transportasi KRL Commuter Line.

Berikut ini adalah tabel jumlah konsumen yang memilih jasa transportasi KRL

Commuter Line dari tanggal 30 april sampai 04 mei jam 08:00 - 10:00.

Tabel 3.1 Jumlah Populasi Penelitian

\begin{tabular}{|c|c|c|}
\hline Hari/Tanggal & Jam & Jumlah \\
\hline Senin/30-04-18 & $08: 00-10: 00$ & 127 \\
\hline Selasa/01-05-18 & $08: 00-10: 00$ & 152 \\
\hline Rabu/02-05-18 & $08: 00-10: 00$ & 82 \\
\hline Kamis/03-05-18 & $08: 00-10: 00$ & 91 \\
\hline Jum'at/04-05-18 & $08: 00-10: 00$ & 79 \\
\hline \multicolumn{2}{|c|}{ Jumlah } & 531 \\
\hline
\end{tabular}

Jumlah sampel digunakan ditentukan dengan menggunakan rumus Slovin:

$n=\frac{N}{1+N e^{2}}$ 


$$
\begin{aligned}
& =\frac{531}{1+531(0,05)^{2}} \\
& =\frac{531}{2,3275}=228,14
\end{aligned}
$$

Keterangan: $\quad \mathrm{N}=$ banyaknya populasi

$$
\mathrm{n}=\text { banyaknya sampel }
$$

$\alpha=$ batas kesalahan pengambilan sampel

Definisi operasional variabel yaitu mengubah konsep - konsep yang masih berupa abstrak dengan kata-kata yang menggambarkan perilaku atau gejala yang dapat di uji dan ditentukan kebenarannya oleh orang lain berdasarkan variabel - variabel yang digunakan. Adapun definisi masing - masing konsep adalah :

1) Pelayanan adalah kemampuan menolong untuk menyediakan segala sesuatu yang diperlukan oleh orang lain diantaranya konsumen.

2) Fasilitas adalah segala sesuatu yang disediakan oleh penyedia jasa.

3) Keamanan adalah keadaan fisik yang aman dari ancaman kecelakaan dan cidera.

4) Kenyamanan adalah suatu kondisi perasaan seseorang yang merasa nyaman.

5) Jarak Tempuh adalah jarak yang dibutuhkan untuk menuju suatu tempat.

6) Waktu Tempuh adalah waktu yang dibutuhkan untuk menuju suatu tempat.

7) Harga adalah nilai jual atau beli produk barang atau jasa.

8) Lokasi adalah tempat penyedia jasa transportasi.

\section{HASIL DAN PEMBAHASAN}

Setelah matriks korelasi terbentuk, maka dilanjutkan dengan uji asumsi untuk mengetahui apakah proses analisis faktor dapat digunakan dalam menginterpretasikan data yang ada. Ukuran yang digunakan sebagai penguji asumsi melalui pengamatan terhadap nilai Keiser - Meyer - Olikn (KMO), hasil uji barlett dan ukuran kecukupan sampling (MSA) dengan menggunakan software SPSS. 
Tabel 4.4 Hasil Uji KMO dan Barlett's Test

KMO and Bartlett's Test

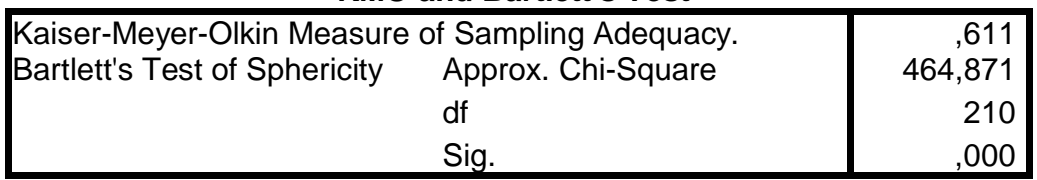

Dari hasil perhitungan diperoleh nilai signifikansi 0,000 yang berarti signifikan dan nilai Bartlett's Test of Sphericity sebesar 464,871. Untuk nilai KMO sebesar 0,611 yang artinya lebih besar dari 0,5 .

Tabel 4.5 Nilai MSA.

\begin{tabular}{|c|c|c|}
\hline Dimensi & Atribut & Nilai MSA \\
\hline \multirow{3}{*}{ Pelayanan } & $\mathrm{X}_{1}$ & 0,554 \\
\cline { 2 - 3 } & $\mathrm{X}_{2}$ & 0,614 \\
\cline { 2 - 3 } & $\mathrm{X}_{3}$ & 0,531 \\
\hline \multirow{3}{*}{ Fasilitas } & $\mathrm{X}_{5}$ & 0,708 \\
\cline { 2 - 3 } & $\mathrm{X}_{6}$ & 0,678 \\
\hline \multirow{3}{*}{ Keamanan } & $\mathrm{X}_{7}$ & 0,642 \\
\cline { 2 - 3 } & $\mathrm{X}_{9}$ & 0,637 \\
\hline \multirow{3}{*}{ Kenyamanan } & $\mathrm{X}_{11}$ & 0,686 \\
\cline { 2 - 3 } & $\mathrm{X}_{13}$ & 0,612 \\
\cline { 2 - 3 } & $\mathrm{X}_{14}$ & 0,553 \\
\hline \multirow{3}{*}{ Jarak Tempuh } & $\mathrm{X}_{15}$ & 0,654 \\
\cline { 2 - 3 } & $\mathrm{X}_{17}$ & 0,531 \\
\cline { 2 - 3 } & $\mathrm{X}_{18}$ & 0,559 \\
\hline \multirow{2}{*}{ Waktu Tempuh } & $\mathrm{X}_{20}$ & 0,599 \\
\cline { 2 - 3 } & $\mathrm{X}_{21}$ & 0,559 \\
\hline \multirow{3}{*}{ Harga } & $\mathrm{X}_{23}$ & 0,587 \\
\cline { 2 - 3 } & $\mathrm{X}_{25}$ & 0,686 \\
\cline { 2 - 3 } & $\mathrm{X}_{26}$ & 0,684 \\
\hline \multirow{2}{*}{ Lokasi } & $\mathrm{X}_{27}$ & 0,604 \\
\cline { 2 - 3 } & $\mathrm{X}_{31}$ & 0,610 \\
\hline & $\mathrm{X}_{31}$ & 0,582 \\
\hline
\end{tabular}

Sedangkan hasil MSA dapat dilihat dari Anti Image Correlation (lampiran 5). Dimana terdapat deretan diagonal angka bertanda 'a' yang menunjukan besaran MSA masing - masing atribut. Angka MSA tiap atribut tidak boleh kurang dari 0,5. Dari informasi Anti Image Correlation sekarang semua indikator mempunyai nilai MSA diatas 0,5 sehingga tidak ada lagi indikator yang perlu dikeluarkan. Dengan demikian, prosedur analisis faktor bisa dimulai setelah mengeluarkan indikator $\mathrm{X}_{22}$ dan $\mathrm{X}_{28}$.

Pada proses ekstraksi, atribut agar diperoleh faktor - faktor yang baru digunakan metode Principal Component Analysis, yang bertujuan untuk mengurangi jumlah variabel menjadi komponen dengan jumlah yang lebih sedikit. 
Tabel 4.6 Nilai Komunalitas (Nilai PCA)

\begin{tabular}{|l|c|c|}
\hline \multicolumn{3}{|c|}{ Communalities } \\
\hline$X_{1}$ & Initial & Extraction \\
$X_{2}$ & 1,000 &, 561 \\
$X_{3}$ & 1,000 &, 521 \\
$X_{5}$ & 1,000 &, 530 \\
$X_{6}$ & 1,000 &, 434 \\
$X_{7}$ & 1,000 &, 471 \\
$X_{9}$ & 1,000 &, 515 \\
$X_{11}$ & 1,000 &, 517 \\
$X_{13}$ & 1,000 &, 447 \\
$X_{14}$ & 1,000 &, 590 \\
$X_{15}$ & 1,000 &, 585 \\
$X_{17}$ & 1,000 &, 474 \\
$X_{18}$ & 1,000 &, 528 \\
$X_{20}$ & 1,000 &, 592 \\
$X_{21}$ & 1,000 &, 465 \\
$X_{23}$ & 1,000 &, 530 \\
$X_{25}$ & 1,000 &, 470 \\
$X_{26}$ & 1,000 &, 462 \\
$X_{27}$ & 1,000 &, 549 \\
$X_{30}$ & 1,000 &, 461 \\
$X_{31}$ & 1,000 &, 599 \\
Extraction Method: Principal \\
Component Analysis. \\
1,000 \\
\hline Man
\end{tabular}

Dari tabel diatas dapat dijelaskan bahwa lokasi stasiun yang dekat dengan rumah membuat suara bising sangat terasa $\left(X_{30}\right)$ mempunyai pengaruh paling besar terhadap minat konsumen (Y) dengan presentase sebesar 0,599.

Hasil yang didapat dari proses ekstrasi faktor yang memiliki eigenvalue lebih besar dari 1 sebanyak 7 faktor. Maka dapat dilihat dari hasil screeplot berikut ini :

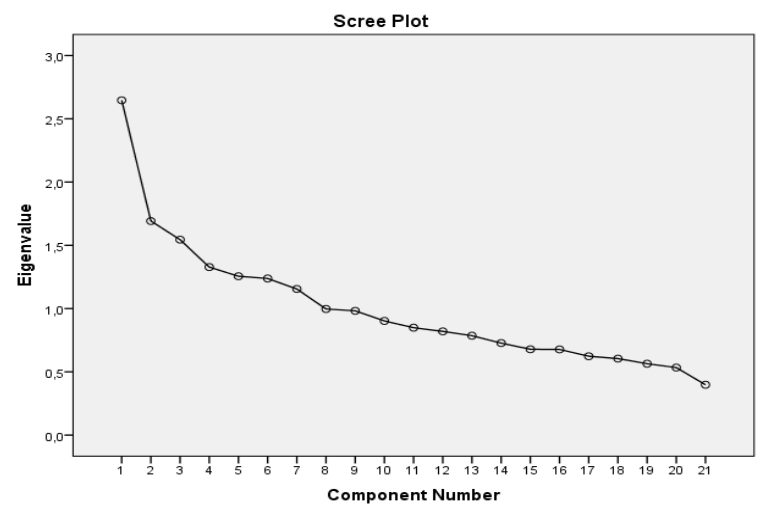

Gambar 4.1 Screeplot pada proses ekstraksi

Dari hasil screeplot diatas terlihat bahwa dari satu ke dua faktor (garis sumbu Component Number $=1$ ke 2) arah garis menurun dengan cukup tajam. Kemudian dari angka 2 ke 3 garis masih menurun, dan dari angka 3 ke 4 pun masih menurun, dan dari angka 4 ke 5 pun masih menurun, dan dari angka 5 ke 6 pun masih menurun, dan dari angka 6 ke 7 pun masih menurun. Demikian pula dari angka 7 ke 8, namun kini dengan slope yang lebih kecil. Juga perhatikan faktor ke 8 sudah di bawah angka 1 dari sumbu 
Y (Eigenvalue). Dari penjelasan diatas dapat ditarik kesimpulan untuk meringkas 21 variabel yaitu $F_{1}, F_{2}, F_{3}, F_{4}, F_{5}, F_{6}$, dan $F_{7}$.

Selanjutnya dilakukan perhitungan nilai total variance explained agar dapat melihat nilai - nilai eigenvalue dan nilai - nilai variance explained untuk masing masing atribut. Seperti pada table dibawah ini.

Tabel 4.7 Total Variance Explained

Total Variance Explained

\begin{tabular}{|c|c|c|c|c|c|c|}
\hline \multirow{2}{*}{ Component } & \multicolumn{5}{|c|}{ Initial Eigenvalues } & \multicolumn{3}{c|}{ Extraction Sums of Squared Loadings } \\
\cline { 2 - 7 } & Total & \% of Variance & Cumulative \% & Total & $\%$ of Variance & Cumulative \% \\
\hline 1 & 2,646 & 12,602 & 12,602 & 2,646 & 12,602 & 12,602 \\
2 & 1,692 & 8,056 & 20,658 & 1,692 & 8,056 & 20,658 \\
3 & 1,545 & 7,355 & 28,013 & 1,545 & 7,355 & 28,013 \\
4 & 1,328 & 6,323 & 34,336 & 1,328 & 6,323 & 34,336 \\
5 & 1,256 & 5,979 & 40,315 & 1,256 & 5,979 & 40,315 \\
6 & 1,238 & 5,894 & 46,208 & 1,238 & 5,894 & 46,208 \\
7 & 1,155 & 5,500 & 51,708 & 1,155 & 5,500 & \\
8 &, 997 & 4,746 & 56,454 & & & \\
9 &, 982 & 4,677 & 61,131 & & & \\
10 &, 902 & 4,296 & 65,427 & & & \\
11 &, 849 & 4,043 & 69,471 & & & \\
12 &, 820 & 3,903 & 73,374 & & & \\
13 &, 786 & 3,741 & 77,115 & & & \\
14 &, 727 & 3,463 & 80,578 & & & \\
15 &, 678 & 3,230 & 83,808 & & & \\
16 &, 677 & 3,224 & 87,032 & & & \\
17 &, 623 & 2,968 & 90,000 & & & \\
18 &, 605 & 2,879 & 92,879 & & & \\
19 &, 564 & 2,687 & 95,565 & & & \\
20 &, 533 & 2,540 & 98,106 & & & \\
21 &, 398 & 1,894 & 100,000 & & & \\
\hline
\end{tabular}

Extraction Method: Principal Component Analysis.

Component berkisar anatara 1 hingga 21 yang mewakili jumlah variabel

independen. Perhatikan kolom initial Eigenvalues yang dengan SPSS kita tentukan nilainya 1. Varians bisa diterangkan oleh faktor 1 adalah 2,646/21 x 100\% $=12,60$, untuk faktor 2 sebesar 1,692/21 x 100\% =8,057, dan untuk faktor 3 sebesar 1,545/21 x $100 \%=7,357$, dan untuk faktor 4 sebesar 1,328/21 x $100 \%=6,323$, dan untuk faktor 5 sebesar $1,256 / 21 \times 100 \%=5,98$, dan untuk faktor 6 sebesar 1,238/21 x 100\% =5,895, serta oleh faktor 7 sebesar 1,155/21 x 100\% = 5,5 dan total ke tujuh faktor akan mampu menjelaskan variabel sebesar $12,60+8,057+7,357+6,323+5,98+5,895+5,5=$ $51,712 \%$. Dengan demikian, karena nilai Eigenvalues yang ditetapkan 1, maka nilai total yang akan diambil adalah yang > 1 yaitu component $1,2,3,4,5$, 6, dan 7 .

Setelah kita menegtahui bahwa faktor maksimal yang bisa terbentuk adalah 7 , selanjutnya kita melakukan penentuan masing - masing variabel independen akan masuk ke dalam faktor 1 , faktor 2 , faktor 3 , faktor 4 , faktor 5 , faktor 6 , atau faktor 7 . Cara menentukannya adalah dengan melihat tabel Component Matrix sebagai berikut: 
Tabel 4.8 Component Matrix

Component Matrix ${ }^{\mathrm{a}}$

\begin{tabular}{|l|c|c|c|c|c|c|c|}
\hline & \multicolumn{7}{|c|}{ Component } \\
\cline { 2 - 8 } & 1 & 2 & 3 & 4 & 5 & 6 & 7 \\
\hline$X_{7}$ &, 543 &,- 114 &,- 069 &, 081 &, 061 &,- 410 &,- 155 \\
$X_{26}$ &, 474 &, 210 &,- 177 &,- 186 &,- 273 &, 208 &,- 310 \\
$X_{15}$ &, 469 &,- 257 &,- 043 &,- 195 &,- 296 &, 039 &,- 243 \\
$X_{14}$ &, 464 &, 138 &, 282 &,- 182 &,- 177 &,- 454 &, 027 \\
$X_{25}$ &, 434 &, 016 &, 303 &,- 025 &, 166 &,- 037 &,- 391 \\
$X_{6}$ &, 390 &,- 255 &,- 150 &, 378 &,- 011 &,- 206 &, 214 \\
$X_{5}$ &, 379 &,- 291 &, 296 &, 098 &,- 278 &, 173 &, 039 \\
$X_{31}$ &, 241 &, 603 &,- 090 &,- 014 &, 267 &, 020 &,- 236 \\
$X_{21}$ &, 137 &, 540 &,- 034 &,- 082 &,- 071 &,- 325 &, 318 \\
$X_{27}$ &, 277 &, 466 &,- 225 &,- 169 &,- 212 &, 175 &, 110 \\
$X_{17}$ &, 406 &,- 118 &,- 547 &,- 040 &,- 196 &, 020 &, 098 \\
$X_{13}$ &, 284 &, 019 &, 523 &, 400 &,- 160 &, 118 &,- 190 \\
$X_{20}$ &, 131 &, 306 &, 474 &, 206 &, 058 &,- 036 &, 287 \\
$X_{9}$ &, 229 &,- 229 &,- 397 &, 050 &, 380 &,- 194 &,- 264 \\
$X_{3}$ &, 362 &, 030 &, 283 &,- 499 &, 100 &,- 003 &, 243 \\
$X_{23}$ &, 277 &,- 033 &,- 133 &, 463 &, 204 &,- 218 &, 266 \\
$X_{30}$ &, 304 &, 435 &,- 171 &, 443 &, 139 &, 247 &,- 109 \\
$X_{1}$ &, 251 &, 064 &,- 004 &,- 275 &, 580 &, 252 &, 137 \\
$X_{2}$ &, 306 &,- 340 &, 248 &,- 152 &, 458 &, 132 &, 008 \\
$X_{18}$ &, 351 &,- 079 &,- 041 &, 193 &,- 036 &, 603 &, 243 \\
$X_{11}$ &, 399 &,- 226 &,- 142 &,- 157 &,- 047 &, 041 &, 434 \\
\hline
\end{tabular}

Extraction Method: Principal Component Analysis.

a. 7 components extracted.

\section{PEMBAHASAN}

Dari kedua puluh satu faktor yang diteliti, dengan proses factoring bisa direduksi menjadi 7 faktor yaitu faktor :

a) Faktor satu $\left(F_{1}\right)$ terdiri atas variabel independen, yaitu :

1) Saya merasa nyaman dengan disediakannya fasilias khusus gerbong untuk wanita $\left(\mathrm{X}_{15}\right)$.

2) Jarak tempuh dari rumah menuju stasiun lebih dekat $\left(\mathrm{X}_{17}\right)$.

3)Saya merasa kecewa karena dengan membayar tiket tidak menjamin saya merasakan fasilitas yang disediakan $\left(\mathrm{X}_{26}\right)$.

Karena korelasi $\mathrm{X}_{15}, \mathrm{X}_{17}, \mathrm{X}_{26}$ adalah positif 0,608 , maka faktor tersebut berpengaruh dengan minat konsumen dalam menggunakan Jasa Transportasi KRL Commuter Line.

b) Faktor dua $\left(\mathrm{F}_{2}\right)$ terdiri atas variabel independen, yaitu :

1)Saya kecewa fasilitas tempat duduk untuk konsumen berkebutuhan khusus sering disalahgunakan oleh konsumen lain $\left(\mathrm{X}_{6}\right)$.

2) Saya senang fasilitas yang disediakan di KRL Commuter Line sudah sangat memadai $\left(\mathrm{X}_{7}\right)$.

3) Saya merasa aman dengan hadirnya petugas keamanan disetiap gerbong $\left(\mathrm{X}_{9}\right)$.

4)Waktu tempuh dari stasiun menuju kantor atau sekolah lebih cepat $\left(X_{23}\right)$. 
Karena korelasi $\mathrm{X}_{6}, \mathrm{X}_{7}, \mathrm{X}_{9}, \mathrm{X}_{23}$ adalah negatif -0,277, maka faktor tersebut tidak berpengaruh dengan minat konsumen dalam menggunakan Jasa Transportasi KRL Commuter Line.

c) Faktor tiga $\left(\mathrm{F}_{3}\right)$ terdiri atas variabel independen, yaitu :

1)Lokasi stasiun yang dekat dengan rumah membuat suara bising sangat terasa $\left(\mathrm{X}_{30}\right)$.

2)Mudahnya akses untuk menuju lokasi stasiun membuat saya lebih memilih transportasi KRL Commuter Line $\left(\mathrm{X}_{31}\right)$.

Karena korelasi $\mathrm{X}_{30}, \mathrm{X}_{31}$ adalah negatif $-0,246$, maka faktor tersebut tidak berpengaruh dengan minat konsumen dalam menggunakan Jasa Transportasi KRL Commuter Line.

d) Faktor empat $\left(\mathrm{F}_{4}\right)$ terdiri atas variabel independen, yaitu :

1)Saya senang pihak penyedia jasa transportasi KRL Commuter Line menyediakan fasilitas tempat duduk untuk konsumen berkebutuhan khusus $\left(\mathrm{X}_{5}\right)$.

2) Saya merasa nyaman dengan berbagai fasilitas yang disediakan $\left(X_{13}\right)$.

3) Seringnya kesalahan teknis membuat kita turun distasiun yang bukan tujuan dan membuat jarak tempuh semakin jauh $\left(\mathrm{X}_{20}\right)$.

4) Harga tiket yang dibayarkan sesuai dengan fasilitas yang disediakan $\left(X_{25}\right)$.

Karena korelasi $\mathrm{X}_{5}, \mathrm{X}_{13}, \mathrm{X}_{20}, \mathrm{X}_{25}$ adalah positif 0,419 tetapi kurang dari 0,5 maka faktor tersebut tidak berpengaruh dengan minat konsumen dalam menggunakan Jasa Transportasi KRL Commuter Line.

e) Faktor lima $\left(\mathrm{F}_{5}\right)$ terdiri atas variabel independen, yaitu :

1)Saya senang dengan bentuk pelayanan yang diberikan oleh petugas KRL Commuter Line $\left(\mathrm{X}_{1}\right)$.

2)Petugas layanan KRL Commuter Line kurang menunjukan keramahan $\left(X_{2}\right)$.

3) Saya senang dengan kesigapan petugas KRL Commuter Line dalam menanggapi berbagai keluhan $\left(\mathrm{X}_{3}\right)$.

Karena korelasi $\mathrm{X}_{1}, \mathrm{X}_{2}, \mathrm{X}_{3}$ adalah positif 0,716 , maka faktor tersebut berpengaruh dengan minat konsumen dalam menggunakan Jasa Transportasi KRL Commuter Line.

f) Faktor enam $\left(\mathrm{F}_{6}\right)$ terdiri atas variabel independen, yaitu :

1) Saya merasa perlu diadakannya penambahan fasilitas $\left(X_{14}\right)$. 
2) Waktu tempuh dari rumah menuju stasiun lebih cepat $\left(X_{21}\right)$.

3)Saya senang dengan kebijakan tiket gratis untuk anak - anak dengan tinggi badan kurang dari $90 \mathrm{~cm}\left(\mathrm{X}_{27}\right)$.

Karena korelasi $\mathrm{X}_{14}, \mathrm{X}_{21}, \mathrm{X}_{27}$ adalah negatif -0,392, maka faktor tersebut tidak berpengaruh dengan minat konsumen dalam menggunakan Jasa Transportasi KRL Commuter Line.

g) Faktor tujuh $\left(\mathrm{F}_{7}\right)$ terdiri atas variabel independen, yaitu :

1)Saya merasa aman dengan diberikannya informasi mengenai situasi darurat $\left(\mathrm{X}_{11}\right)$.

2)Seringnya timbul kemacetan didekat stasiun terkadang mengharuskan mencari jalan alternative lain dan membuat jarak semakin jauh $\left(\mathrm{X}_{18}\right)$.

Karena korelasi $\mathrm{X}_{11}, \mathrm{X}_{18}$ adalah positif 0,570, maka faktor tersebut berpengaruh dengan minat konsumen dalam menggunakan Jasa Transportasi KRL Commuter Line.

\section{KESIMPULAN}

Berdasarkan hasil dan pembahasan, penulis memperoleh berbagai kesimpulan sebagai berikut:

1) Banyaknya faktor yang terbentuk dari proses reduksi adalah 7 faktor. Faktor satu (F1) terdiri dari X15, X26 dan X17 dengan nilai korelasi 0,608. Faktor dua (F2) terdiri dari $\mathrm{X} 6, \mathrm{X} 23, \mathrm{X} 7$, dan $\mathrm{X} 9$ dengan nilai korelasi $-0,277$. Faktor tiga (F3) terdiri dari X31 dan X30 dengan nilai korelasi -0,246. Faktor empat (F4) terdiri dari X13, X5, X20, dan X25 dengan nilai korelasi 0,419. Faktor lima (F5) terdiri dari $\mathrm{X} 1, \mathrm{X} 2$, dan X3 dengan nilai korelasi 0,716. Faktor enam (F6) terdiri dari X21, X14, dan X27 dengan nilai korelasi -0,392. Faktor tujuh (F7) terdiri dari X18, dan X11 dengan nilai korelasi 0,570.

2) Berdasarkan analisis faktor, faktor yang paling dominan mempengaruhi minat konsumen dalam menggunakan jasa transportasi KRL Commuter Line adalah Faktor lima (F5) terdiri dari X1, X2, dan X3.

3) Berdasarkan analisis faktor, besar pengaruh faktor yang paling dominan mempengaruhi minat konsumen dalam menggunakan jasa transportasi KRL Commuter Line adalah Faktor lima (F5) dengan nilai korelasi 0,716 atau 71,60\%. 


\section{DAFTAR PUSTAKA}

Agus Widiyanto, Mikha. 2013. Statistika Terapan. Jakarta : PT Elex Media Komputindo.

Gudono. 2012. Analisis Data Multivariat. Yogyakarta : BPFE-Yogyakarta.

Gunawan, Imam. 2016. Pengantar Statistika Inferensial. Jakarta : PT. RajaGrafindo Persada.

Hero S. 2011. Analisis Faktor Faktor Yang Mempengaruhi Konsumen Dalam Memilih Kereta Api Dengan Menggunakan Algoritma Chaid. Skripsi S1.

Jurusan Teknik Industri Universitas Indonesia. Depok.

Ronaldo S. 2015. Analisis Faktor Faktor Yang Mempengaruhi Konsumen Memilih Jasa Angkutan Kereta Api Medan Kuala Namu. Skripsi S1. Jurusan Ekonomi Universitas Sumatra Utara. Medan.

Rustian, Kamaludin. 2003. Ekonomi Transportasi. Jakarta : Ghalia Indonesia.

Santoso, Singgih. 2017. Statistik Multivariat Dengan SPSS. Jakarta : Elex Media Komputindo.

Sugiyono. 2016. Metode Penelitian Kuantitatif Kualitatif R\&D. Bandung : Alfabeta.

Supranto, J. 2010. Analisis Multivariat Arti \& Interpretasi. Jakarta : Rineka Cipta.

Supranto, J. 2013. Petunjuk Praktis Penelitian Ilmiah Untuk Menyusun Skripsi Tesis Dan Disertasi. Jakarta : Mitra Wacana Media.

Susilawati. 2014. Faktor Faktor Yang Mempengaruhi Minat Beli Konsumen Terhadap Rokok A Mild Dengan Menggunakan Analisis Faktor. Skripsi

S1. Jurusan Matematika Universitas Pamulang. Tangerang Selatan.

Widarjono, Agus. 2010. Analisis Statistika Multivariat Terapan. Yogyakarta : UPP STIM YKPN.

Widarjono, Agus. 2015. Analisis Multivariat Terapan. Yogyakarta : UPP STIM YKPN. 